University of Nebraska - Lincoln

DigitalCommons@University of Nebraska - Lincoln

Agronomy \& Horticulture -- Faculty Publications

Agronomy and Horticulture Department

8-2012

\title{
An evaluation of MODIS 8- and 16-day composite products for monitoring maize green leaf area index
}

\author{
Noemi Guindin-Garcia \\ University of Nebraska-Lincoln, nguindin@umd.edu \\ Anatoly A. Gitelson \\ University of Nebraska-Lincoln, agitelson2@unl.edu \\ Timothy J. Arkebauer \\ University of Nebraska-Lincoln, tarkebauer1@unl.edu \\ John Shanahan \\ Pioneer Hi-Bred, Johnston, IA \\ Albert Weiss \\ University of Nebraska-Lincoln, aweiss1@unl.edu
}

Follow this and additional works at: https://digitalcommons.unl.edu/agronomyfacpub

Guindin-Garcia, Noemi; Gitelson, Anatoly A.; Arkebauer, Timothy J.; Shanahan, John; and Weiss, Albert, "An evaluation of MODIS 8- and 16-day composite products for monitoring maize green leaf area index" (2012). Agronomy \& Horticulture -- Faculty Publications. 678.

https://digitalcommons.unl.edu/agronomyfacpub/678

This Article is brought to you for free and open access by the Agronomy and Horticulture Department at DigitalCommons@University of Nebraska - Lincoln. It has been accepted for inclusion in Agronomy \& Horticulture -Faculty Publications by an authorized administrator of DigitalCommons@University of Nebraska - Lincoln. 


\title{
An evaluation of MODIS 8- and 16-day composite products for monitoring maize green leaf area index
}

\author{
Noemi Guindin-Garcia, ${ }^{1}$ Anatoly A. Gitelson, ${ }^{2}$ Timothy J. Arkebauer, ${ }^{1}$ \\ John Shanahan, ${ }^{3}$ and Albert Weiss ${ }^{4}$ \\ 1. Department of Agronomy and Horticulture, University of Nebraska-Lincoln, 203 KCR, Lincoln, NE 68583-0817, \\ USA \\ 2. Center for Advanced Land Management Information Technologies (CALMIT), School of Natural Resources, 303 \\ Hardin Hall, University of Nebraska-Lincoln, Lincoln, NE 68583-0973, USA \\ 3. Pioneer Hi-Bred, Johnston, IA 50131-1000, USA \\ 4. School of Natural Resources, 507 Hardin Hall, University of Nebraska-Lincoln, Lincoln, NE 68583-0995, USA \\ Corresponding author - A. A. Gitelson, agitelson2@unl.edu
}

\begin{abstract}
The seasonal patterns of green leaf area index (GLAI) can be used to assess crop physiological and phenological status, to assess yield potential, and to incorporate in crop simulation models. This study focused on examining the potential capabilities and limitations of satellite data retrieved from the moderate resolution imaging spectroradiometer (MODIS) 8- and 16-day composite products to quantitatively estimate GLAI over maize (Zea mays L.) fields. Results, based on the nine years of data used in this study, indicated a wide variability of temporal resolution obtained from MODIS 8- and 16-day composite periods and highlighted the importance of information about day of MODIS products pixel composite for monitoring agricultural crops. Due to high maize GLAI temporal variability, the inclusion of day of pixel composite is necessary to decrease substantial uncertainties in estimating GLAI. Results also indicated that maize GLAI can be accurately retrieved from the 250-m resolution MODIS products (MOD13Q1 and MOD09Q1) by a wide dynamic range vegetation index with root mean square error (RMSE) below $0.60 \mathrm{~m}^{2} \mathrm{~m}^{-2}$ or by the enhanced vegetation index with RMSE below $0.70 \mathrm{~m}^{2} \mathrm{~m}^{-2}$.
\end{abstract}

Keywords: MODIS, temporal resolution, vegetation indices, maize, green leaf area index

\section{Introduction}

Remote sensing has been used to estimate crop biophysical parameters (CBP) such as green leaf area index (GLAI), canopy chlorophyll content, the fraction of photosynthetically active radiation absorbed by the crop, biomass, vegetation cover, and gross primary production using different vegetation indices, VIs (e.g., Hatfield et al., 2008). Most of the VIs are combinations of reflectance in the visible or photosynthetically active radiation spectral range $(400-700 \mathrm{~nm})$, especially red reflectance $(620-700 \mathrm{~nm})$, and the near infrared range (NIR; $750-1300 \mathrm{~nm}$ ). The most widely used VI in agricultural applications is the normalized difference vegetation index, NDVI (Rouse et al., 1974). Myneni et al. (1997) developed a physically based algorithm for the estimation of GLAI from NDVI observations. As the authors noted, "the algorithm must be viewed within a framework dominated largely by practical consideration and to a lesser extent by accuracy". The relationship between NDVI and GLAI is essentially nonlinear and exhibits significant variations among various vegetation types. When GLAI exceeds $2 \mathrm{~m}^{2} \mathrm{~m}^{-2}$, NDVI is generally insensitive for assessing changes in GLAI in grasses, cereal crops, and broadleaf crops (Myneni et al., 1997; Gitelson, 2004). New approaches have been proposed using spectral regions in the green and red edge (Buschman and Nagel, 1993; Gitelson et al., 1996; Dash and Curran, 2004; Gitelson, 2004). However, data from the red edge spectral region are not available from the widely used the moderate resolution imaging spectroradiometer (MODIS) sensor and the green band is only available in the 500-m resolution MODIS product.

Huete et al. (1997) introduced the enhanced vegetation index (EVI), which has a higher sensitivity to moderate-to-high vegetation biomass; EVI is a widely used product of the MODIS system:

$$
\text { EVI }=\frac{2.5 \times\left(\rho_{\text {NIR }}-\rho_{\text {red }}\right)}{1+\rho_{\text {NIR }}+6 \times \rho_{\text {red }}-7.5 \times \rho_{\text {blue }}}
$$

The modification of EVI, EVI2, uses only red and NIR bands (Jiang et al., 2008):

$$
\mathrm{EVI} 2=\frac{2.5 \times\left(\rho_{\mathrm{NIR}}-\rho_{\mathrm{red}}\right)}{1+\rho_{\mathrm{NIR}}+2.4 \times \rho_{\mathrm{red}}}
$$


Gitelson (2004) proposed a nonlinear transformation of NDVI, called the wide dynamic range vegetation index (WDRVI), in the form:

$$
\text { WDRVI }=\frac{\alpha \times \rho_{\mathrm{NIR}}-\rho_{\text {red }}}{\alpha \times \rho_{\mathrm{NIR}}+\rho_{\text {red }}}
$$

The weighting coefficient, $\alpha$ is introduced to attenuate the contribution of the NIR reflectance at moderate-to-high green biomass, and to make it comparable to that of the red reflectance. It was shown that WDRVI retrieved from close range $(6 \mathrm{~m}$ above the canopy) and from MODIS data is linearly related to GLAI (Gitelson et al., 2007; Gitelson, 2011). WDRVI can be calculated using MODIS red and NIR reflectances (Equation (2a)) or directly from NDVI (Viña and Gitelson, 2005):

$$
\text { WDRVI }=\frac{(\alpha+1) \times \mathrm{NDVI}+(\alpha-1)}{(\alpha-1) \times \mathrm{NDVI}+(\alpha+1)}
$$

The accuracy of CBP estimates depends on the satellite system's temporal and spatial resolutions, and the quality of the data due to appearance of clouds, low viewing angles, and poor geometry (Chen et al., 2002, 2003; Duchemin and Maisongrande, 2002). It has been demonstrated that without cloud contamination NDVI is able to quite accurately detect maximum values of maize GLAI (e.g., Chen et al., 2003). In addition to atmospheric interference (e.g., clouds, haze, etc.), NDVI also could be affected by contamination from surrounding areas due to limited spatial resolution. Smoothing the data obtained from VIs over study areas reduces effects of contaminated signals (Swets et al., 1999; Funk and Budde, 2009). An alternative to reduce or eliminate pixel contamination is the selection of finer spatial resolution. Data obtained from a spatial resolution of 250-m (area is about $6.25 \mathrm{ha}$ ) allow quite accurate identification of pixels covered by specific crops (Gitelson et al., 2007).

The estimation of CBP and the detection of developmental stages of agricultural crops are important for government agencies, private industry, and researchers. MODIS products offer high quality data at consistent spatial resolutions and temporal resolutions derived every 8 or 16 days (Huete et al., 1999, 2002; Didan and Huete, 2006). MODIS 8- and 16-day composites contain the best possible observations obtained during the composite period based on several parameters such as view angle, absence of clouds or cloud shadows and aerosols (Vermote and Kotchennova, 2008). MODIS 8- and 16-day composite data have been used in many agricultural applications to develop land cover/land use products (Lobell and Asner, 2004; Sedano et al., 2005; Lunetta et al., 2006), monitor phenology (Zhang et al., 2003; Sakamoto et al., 2005; Wardlow et al., 2006), and estimate CBP (Zhu et al., 2005; Chen et al., 2006; Rochdi and Fernandes, 2010).

MODIS products have also been used to estimate GLAI for crop modeling applications. Fang et al. (2008) utilized the MODIS LAI 1000-m product to incorporate into a maize crop simulation model. Doraiswamy et al. (2004) used data retrieved from MODIS 250-m surface reflectance 8-day composite in a radiative transfer model to estimate GLAI during the growing season and then incorporated GLAI into a maize crop simulation model. Chen et al. (2006) evaluated the potential use of data retrieved from MODIS at 250-, 500- and 1000-m resolutions to track maize GLAI and phenology for crop modeling applications. However, a detailed evaluation of the effects of MODIS temporal resolution on the accuracy of crop GLAI estimates has not been reported to date.

Monitoring of maize GLAI requires a good understanding of GLAI changes at each phenological stage in order to evaluate potential capabilities and limitations of the satellite data retrieved from MODIS 8- and 16-day composite periods. A pe- riod of 8 and/or 16 days may represent significant changes in maize GLAI especially during the vegetative stage. For example, maximum observed rate of maize GLAI change during the period of this study was as large as $0.30 \mathrm{~m}^{2} \mathrm{~m}^{-2}$ day $^{-1}$. Consequently, information on day of pixel composite (DPC), included in some MODIS products, would appear to be very useful for accurately estimating GLAI in maize.

The main goal of this study was to evaluate the accuracy of maize GLAI estimates from three MODIS products: (a) MODIS vegetation index 16-day composite 250-m (MOD13Q1), (b) MODIS surface reflectance 8-day composite 250-m (MOD09Q1), and (c) MODIS surface reflectance 8-day composite 500-m (MOD09A1). Specifically, we (i) investigated real temporal resolution of 8- and 16-day composite periods and demonstrated the importance of the day of pixel composite information for increasing the accuracy of maize GLAI estimates; and (ii) calibrated and validated models for estimating maize GLAI.

\section{Materials and methods}

\subsection{Field measurements}

This research used field data from the Carbon Sequestration Project at the University of Nebraska-Lincoln located at the Agricultural Research and Development Center in Saunders County, Nebraska, USA. Field data were collected over three large study sites with different cropping systems. Site $1\left(41^{\circ} 09^{\prime} 54.2^{\prime \prime} \mathrm{N}, 96^{\circ} 28^{\prime} 35.9^{\prime \prime} \mathrm{W}, 361 \mathrm{~m}\right)$ was 48.7 ha planted in continuous maize from 2001 until 2009 under irrigated (center pivot) conditions. Site $2\left(41^{\circ} 09^{\prime} 53.5^{\prime \prime} \mathrm{N}, 96^{\circ} 28^{\prime} 12.3^{\prime \prime} \mathrm{W}\right.$, $362 \mathrm{~m}$ ) was planted in maize-soybean rotation over an area of 52.4 ha under center pivot irrigation. Site $3\left(41^{\circ} 10^{\prime} 46.8^{\prime \prime} \mathrm{N}\right.$, $96^{\circ} 26^{\prime} 22.7^{\prime \prime} \mathrm{W}, 362 \mathrm{~m}$ ) was 65.4 ha planted in a maize-soybean rotation under rain-fed conditions. The soils at the three sites are deep silty clay loams consisting of four soil series: Yutan (fine-silty, mixed, superactive, mesic Mollic Hapludalfs), Tomek (fine, smectitic, mesic Pachic Argialbolls), Filbert (fine, smectitic, mesic Vertic Argialbolls), and Filmore (fine, smectitic, mesic Vertic Argialbolls). Nitrogen (N) was applied in one application at the rain-fed site (site 3) and three applications at the irrigated sites (sites 1 and 2) according to guidelines recommended in Shapiro et al. (2001). This study used nine years of data (2001-2009) from site 1 and five years of data (2001, 2003, 2005, 2007, and 2009) from sites 2 and 3. Within each site, six plot areas $(20 \mathrm{~m} \times 20 \mathrm{~m})$ were established and called intensive management zones (IMZs) for detailed process-level studies (details in Verma et al., 2005). Destructive samples consisting of five or more continuous plants were collected from a $1 \mathrm{~m}$ linear row section in the six IMZs for each site at 10- to 14-day intervals until maturity. Leaves were separated into green and non-green portions and total and green leaf areas harvested per plant $\left(\mathrm{m}^{2}\right.$ plant $\left.^{-1}\right)$ were measured with an area meter (Model LI-3100, LI-COR, Inc., Lincoln, NE). In each IMZ, the total and green LAI were calculated using the plant population density (plants $\mathrm{m}^{-2}$ ) by:

$$
\begin{aligned}
\text { Total LAI } & =\frac{\text { plant population } \times \text { total leaf area }}{\text { plant }} \\
\text { GLAI } & =\frac{\text { plant population } \times \text { green leaf area }}{\text { plant }}
\end{aligned}
$$

Total LAI and green LAI were obtained by averaging all six IMZ measurements at each site. The mean standard error of GLAI measurements was less than $0.15 \mathrm{~m}^{2} \mathrm{~m}^{-2}$ during the nine years of study. Cubic spline interpolation (in MATLAB ${ }^{\circledR}$ ) was used to estimate daily values of total LAI and GLAI. 

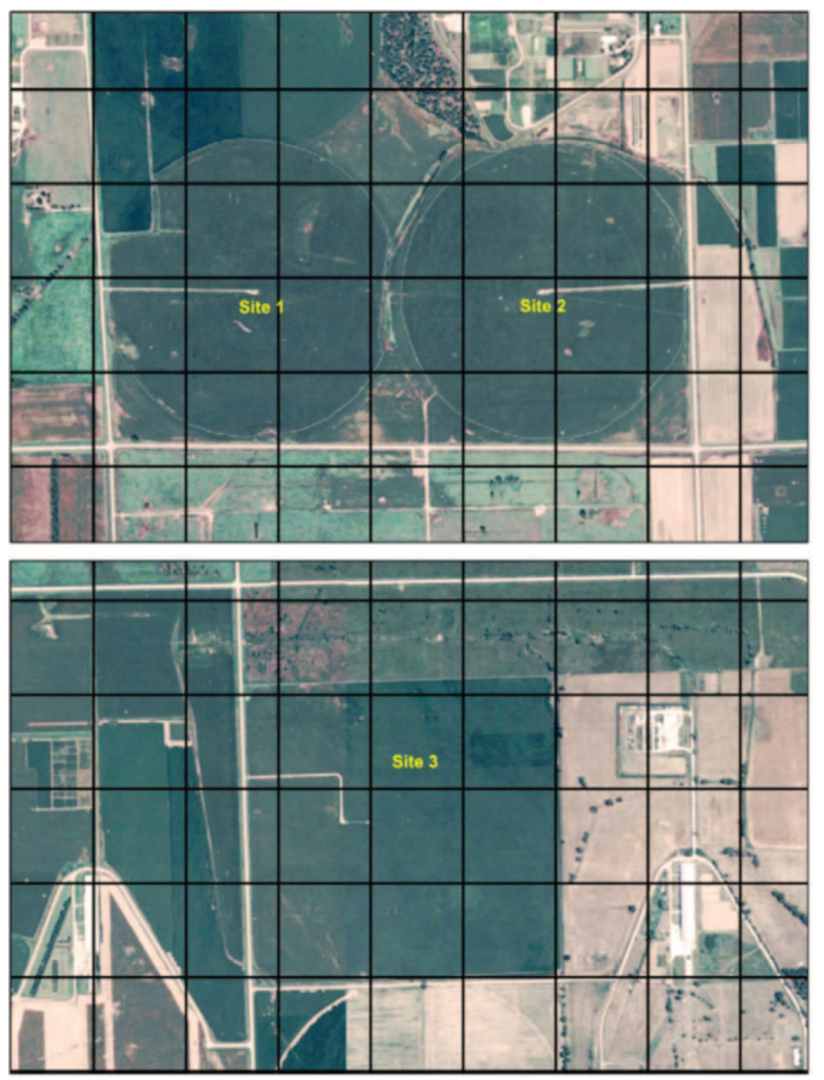

Figure 1. MODIS 250-m 16-day composite (MOD13Q1) pixel locations superimposed over study sites in Mead, Nebraska.

\subsection{Remote sensing data}

A time series of MODIS Terra vegetation index 16-day composite 250-m (MOD13Q1), MODIS surface reflectance 8-day composite 250-m (MOD09Q1), and MODIS surface reflectance 8-day composite 500-m (MOD09A1) images were downloaded from the National Aeronautic and Space Administration (NASA) Land Process Distributed Active Archive Center (LPDAAC) ( https://lpdaac.usgs.gov/lpdaac/get_data/data_pool ) for the study area for the April through October period from 2001 until 2009 (MODIS tile h10v04). All MODIS images were processed, reprojected, and converted to the GeoTIFF format using the MODIS Reprojection Tool Version 4.0 (MRT) downloaded from LPAAC ( https://lpdaac.usgs.gov/lpdaac/tools ). The day of year (DOY) for each MODIS image represents the first day of the period of the 8- or 16-day composite. The day during the composite period when the best observation is recorded is called the day of pixel composite. Information on DPC is included in the MOD09A1 and MOD13Q1 products but it is not available in the MOD09Q1 product. We assumed that the DPC during the 8-day composite periods for the MOD09Q1 product were the same as for the MOD09A1 product.

MOD09A1 provides surface reflectance in 7 bands (band $1=620-670 \mathrm{~nm}$; band $2=841-876 \mathrm{~nm}$; band $3=459-479 \mathrm{~nm}$; band $4=545-565 \mathrm{~nm}$; band $5=1230-1250 \mathrm{~nm}$; band $6=1628-$ $1652 \mathrm{~nm}$; band $7=2105-2155 \mathrm{~nm}$ ) with resolution of 500-m. MOD09Q1 provides reflectance values for bands 1 and 2 . MOD13Q1 included data for NDVI and EVI, and surface reflectances from bands 1, 2, 3, and 7 with 250-m resolution. Each study site was geolocated on each MOD13Q1 (Figure 1). To avoid pixel contamination, we used NDVI and EVI from pixels located as close as possible to the center of the field. Because the spatial resolution of MOD13Q1 and MOD09Q1 is the
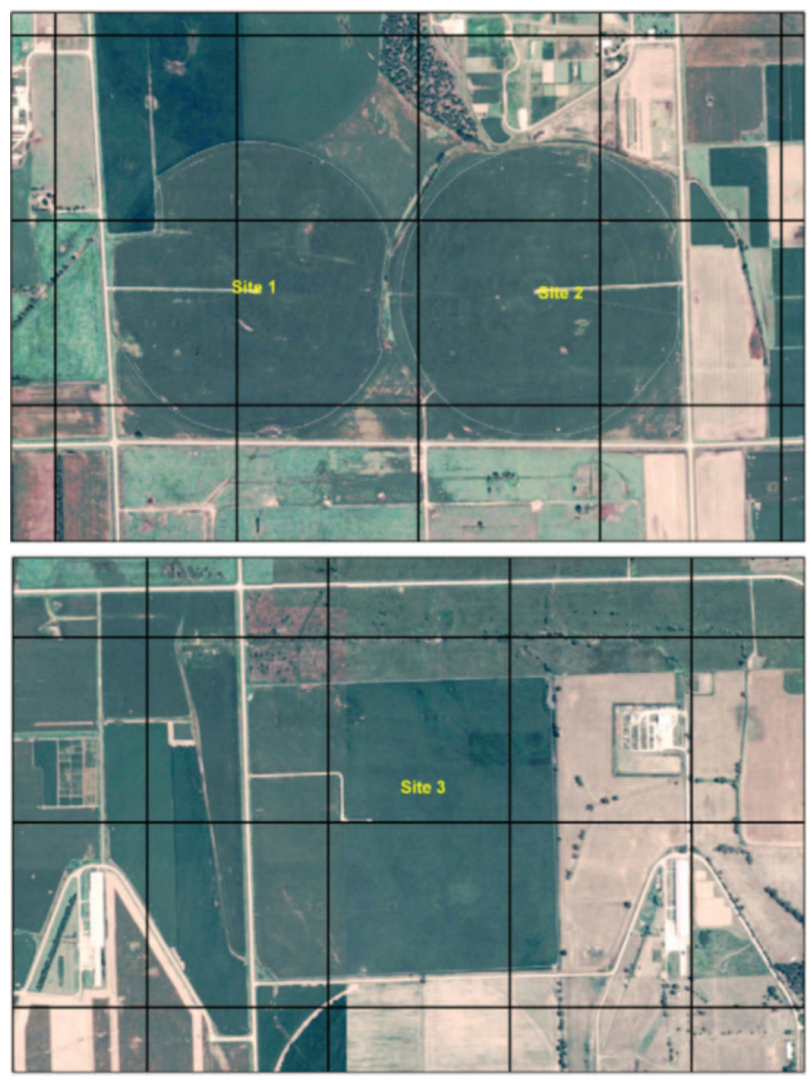

Figure 2. MODIS 500-m 8-day composite (MOD09A1) pixel locations superimposed over study sites in Mead, Nebraska.

same (250-m), the locations of selected pixels from MOD13Q1 were also used to retrieve reflectance data from MOD09Q1 over the study sites. A similar technique was used to retrieve data from MOD09A1 (Figure 2). However, due to the size of the field sites, it was not possible to select an uncontaminated pixel in each $500-\mathrm{m}$ resolution image.

Surface reflectances from bands 1 and 2 were extracted from MOD09Q1 and MOD09A1 products and NDVI and WDRVI were calculated for the selected pixels in each study site from 2001 until 2009. EVI and EVI2 (Jiang et al., 2008) were calculated using MOD09A1 and MOD09Q1 products. Average values of NDVI, EVI, and WDRVI of the selected pixels were used for further analysis.

EVI and EVI2 were very closely related: determination coefficient, $R^{2}$, was above 0.96 for MOD09A1 and 0.99 for MOD13Q1. Thus, from this point onward EVI2 will be referred to as EVI for data retrieved from the MOD09Q1 product.

Direct measurements of GLAI under rain-fed and irrigated conditions from 2001 until 2004 were used to calibrate models for GLAI estimation using NDVI, EVI, and WDRVI. The WDRVI was calculated using Equations (2a) and (2b) with two weighting coefficients $\alpha=0.1$ and 0.2 . The models were validated with independent field data taken from 2005 to 2009 under rain-fed and irrigated conditions and the root mean square error (RMSE) of GLAI prediction was found for each model.

To test the applicability of VIs to estimate GLAI using different MODIS products with no re-parameterization of the GLAI vs. VIs relationship, we performed an analysis of variance (ANOVA) between the coefficients of the best-fit functions for three products (8- and 16-day composites with 250-m resolution and 8-day composite with $500-\mathrm{m}$ resolution) combined vs. the coefficients obtained for each individual product (Ritz and Streibig, 2008). 

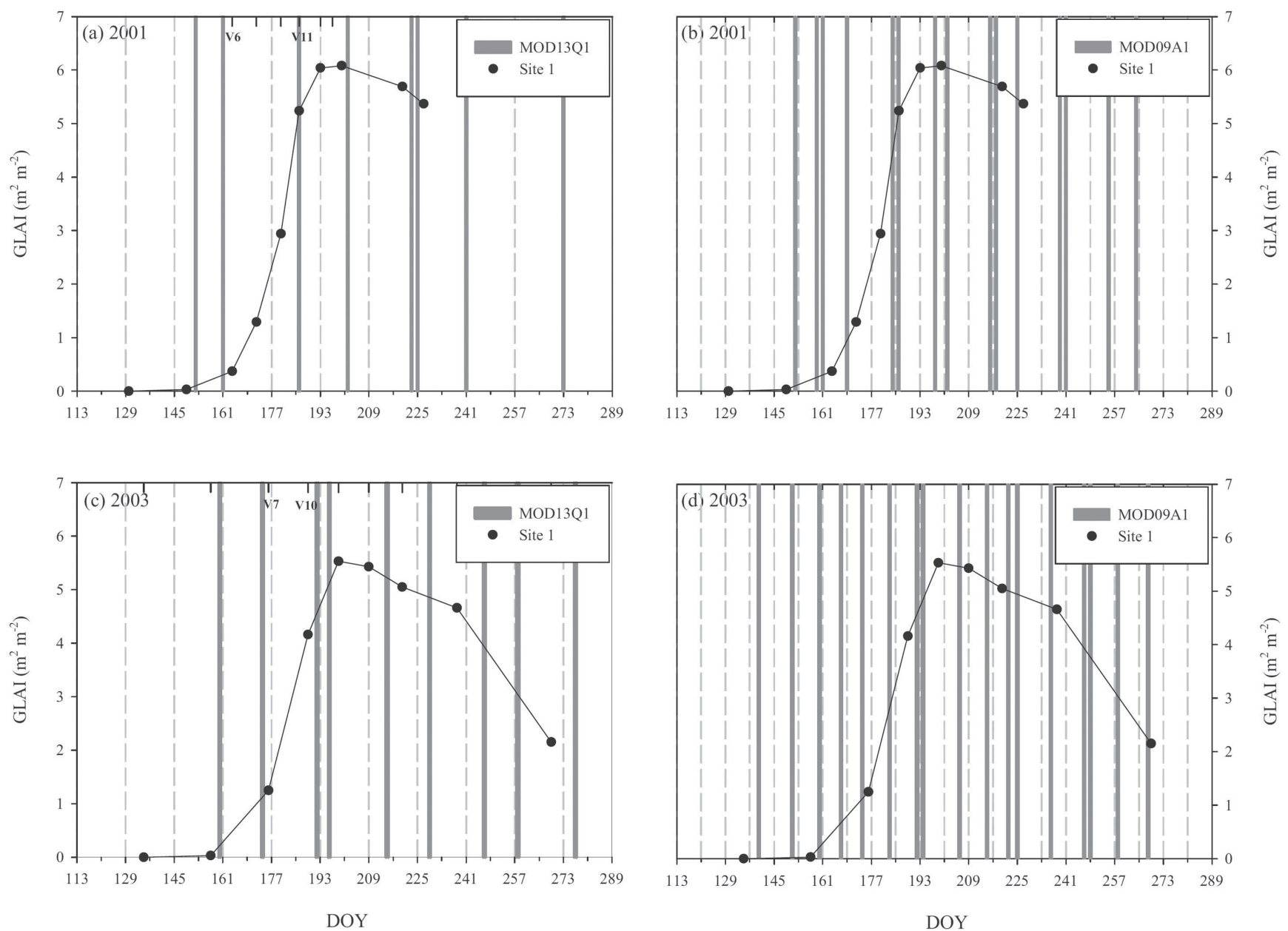

Figure 3. Green leaf area index (GLAI) plotted vs. of day of year (DOY). Solid bars correspond to MODIS day of pixel composite and dashed lines correspond to MODIS first day of composite period. MODIS vegetation index 250-m 16-day composite (MOD13Q1) in 2001 (a), 2003 (c) and MODIS surface reflectance 500-m 8-day composite (MOD09A1) in 2001 (b) and 2003 (d).

To determine the accuracy of GLAI estimation, we employed the noise equivalent (NE) of GLAI (Govaerts et al., 1999; Viña and Gitelson, 2005) that was calculated as:

$$
\mathrm{NE} \Delta \mathrm{GLAI}=\frac{\mathrm{RMSE}(\mathrm{VIs} \text { vs. GLAI })}{[d(\mathrm{VIs}) / d(\mathrm{LAI}]}
$$

where $d$ (VIs) / $d$ (GLAI) is the first derivative of VIs with respect to GLAI and RMSE(VIs vs. GLAI) is the root mean square error of the VIs vs. GLAI relationship. The NE $\triangle$ GLAI provides a measure of how well the VIs responds to GLAI across its entire range of its variation. NE $\triangle$ GLAI takes into account not only the RMSE of the GLAI estimation but also accounts for the sensitivity of the VIs to GLAI, thus providing a metric accounting for both scattering of the points from the best fit function and the slope of the best fit function.

\section{Results and discussion}

\subsection{Temporal resolution}

Temporal behavior of maize GLAI as a function of day of year is shown in Figure 3. The DPC from MOD13Q1 and MOD09A1 products is represented by solid bars while the first day of the 16- and 8-day composites is represented by dashed bars. The real MODIS temporal resolution is a period between two consecutive observations, i.e., between two successive days of pixel composite, thus, the number of days between the solid bars. It can be seen that during the growing season the temporal resolution changed widely and may exceed the 8- or 16-day composite period. During the nine years of the study, the real observed temporal resolution of the MOD09A1 product (8-day composite) ranged from 1 to 14 days and $50 \%$ of the observations (116 of 231) had a resolution of more than 8 days. The real observed temporal resolution of MOD13Q1 (16-day composite) varied from 2 to 30 days with more than $50 \%$ of the observations (35 of 66) having a resolution of more than 16 days. In other words, MODIS 8- and 16-day composites did not provide data every 8 or 16 consecutive days as has been assumed in previous studies (e.g., Chen et al., 2006; Wardlow et al., 2006). For example, the MOD13Q1 data retrieved from images taken at DOY 209 and 225 were composed on day 223 and 225, respectively, which represents 2 days between the images (Figure 3a) and data retrieved from images taken at DOY 161 and 177 were composed on day 161 and 186, thus, a period of 25 days occurred between the information retrieved from these images (Figure 3a).

The DPC for composite period of 8 or 16 days may represent significant changes in maize GLAI especially during the vegetative stage. Maize GLAI dynamics change according to the crop development stage (Figure 3). During vegetative stages, maize GLAI changes rapidly; in this study daily values of $d(\mathrm{GLAI}) / d(\mathrm{DOY})$ ranged from 0.20 to $0.30 \mathrm{~m}^{2} \mathrm{~m}^{-2}$ day ${ }^{-1}$ under rain-fed and irrigated conditions, respectively. 


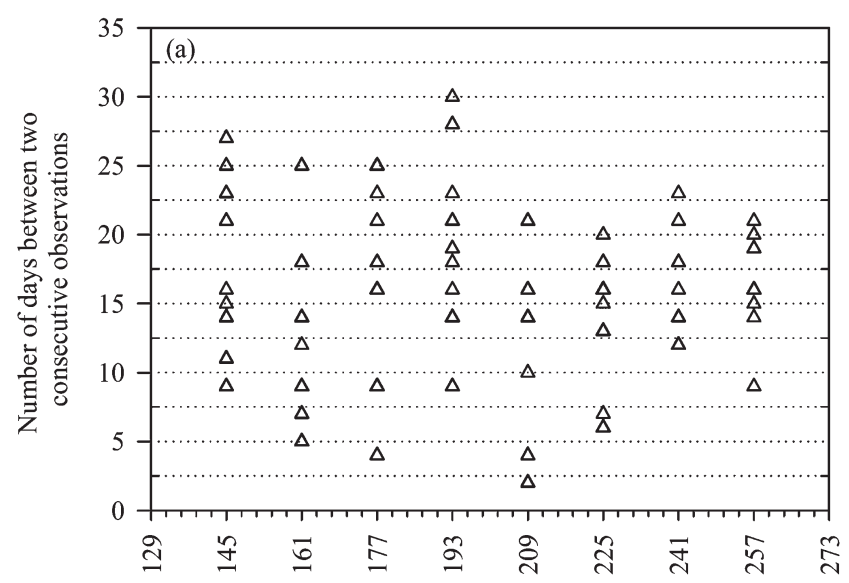

First DOY of MODIS composite period

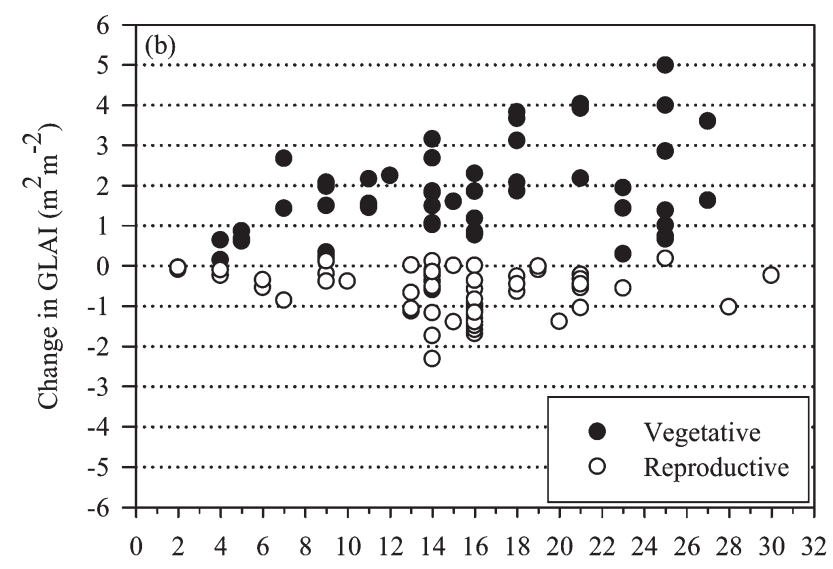

Days between two consecutive observations

Figure 4. (a) Number of days between two consecutive observations plotted vs. the first day of MODIS composite period (DOY) for MODIS vegetation index 250-m 16-day composite period data (MOD13Q1). (b) Changes in green leaf area index (GLAI) plotted vs. number of days between two consecutive observations.

The real temporal resolution of MOD09A1 and MOD13Q1 products varies for each pixel in the image. It can be seen that the DPC changed without any predictable pattern (Figure 4 and Figure 5a). This contradicts assumptions of previous studies that assumed either the first, last, or mean day of the composite period was appropriate (Chen et al., 2006; Wardlow et al., 2006). The real temporal resolution has significant implications in detecting phenology of agricultural crops. Due to the variability in the first derivative of GLAI with respect to DOY, $d(\mathrm{GLAI}) / d(\mathrm{DOY})$, during growing season, differences in GLAI values in a period between two consecutive observations might vary widely depending on the development stage (Figures $4 \mathrm{~b} \&$ $5 b)$. For example, during a 9-day period between two consecutive observations (16-day composite data), change in GLAI may be up to $4 \mathrm{~m}^{2} \mathrm{~m}^{-2}$ during the vegetative stages while it could be less than $1 \mathrm{~m}^{2} \mathrm{~m}^{-2}$ during reproductive stages (Figure $4 \mathrm{~b}$ ). Similar results were observed for the 8-day composite data where changes in maize GLAI were larger during vegetative stages compare to reproductive stages (Figure 5b). However, even using the 8-day composite data, one cannot avoid large uncertainties in GLAI values, ranging from 1 to $3.5 \mathrm{~m}^{2} \mathrm{~m}^{-2}$, when the real temporal resolution - the period between successive observations - exceeds 7 days (Figure 5b). These results highlight that the real temporal resolution of MODIS composite products must be taken into account when MODIS data are used to es-

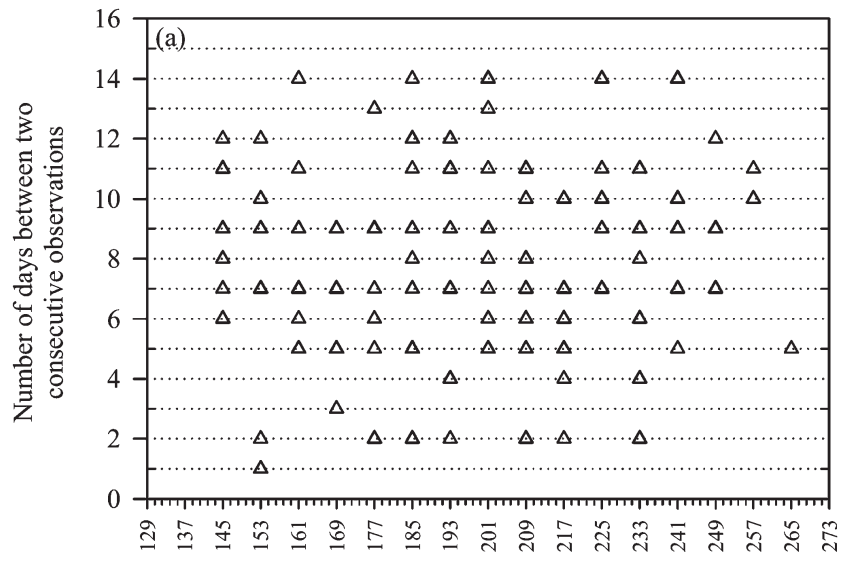

First DOY of MODIS composite period

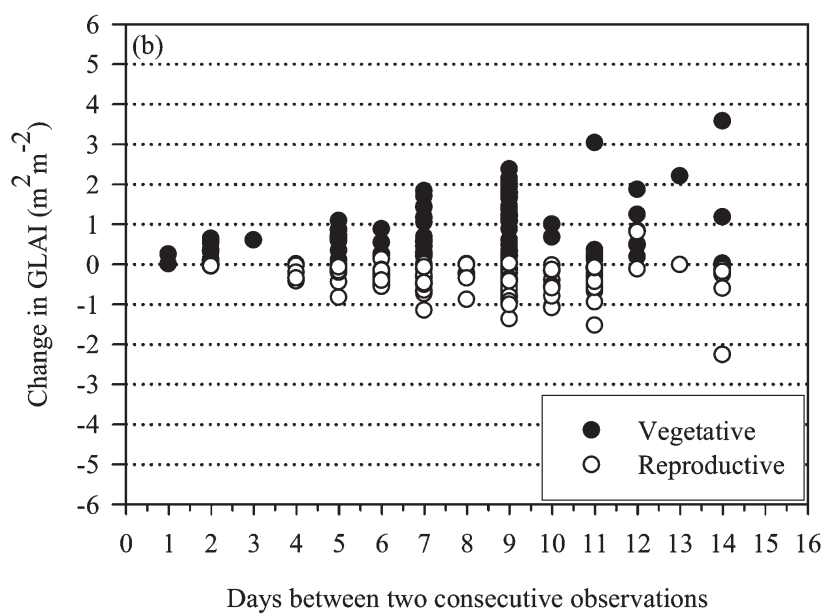

Figure 5. (a) Number of days between two consecutive observations plotted vs. first day of MODIS composite period (DOY) for MODIS surface reflectance 250-m 8-day composite period data (MOD09Q1).

(b) Changes in green leaf area index (GLAI) plotted vs. number of days between two consecutive observations.

timate rapidly changing biophysical characteristics (e.g., GLAI) of agricultural crops such as maize.

MODIS VIs 16-day composites have been used in many agricultural applications such as phenology detection (Zhang et al., 2003; Sakamoto et al., 2005; Wardlow et al., 2006); however, none of these studies mentioned the importance of a period of 16 days on agricultural crop dynamics especially during the vegetative stage. The MODIS 16-day composite (MOD13Q1) data might not be able to detect critical developmental stages of agricultural crops due to periods between observations of up to 30 days (Figure 4a). To evaluate crop condition and yield, a technique comparing NDVI values obtained in a current growing season with historical NDVI values for the same study site has been widely used (e.g., Kastens et al., 2005; Li et al., 2007). However, analyses of historical NDVI data that do not consider DPC may also lead to erroneous interpretations. For instance, during the nine years of observation in our study, NDVI values obtained from MODIS 16-day composite over site 1 on DOY 161 ranged from 0.31 to 0.85 .

\subsection{Estimation of maize green leaf area index}

The first step in testing performance of vegetation indices retrieved from MODIS products was to understand how spatial and temporal resolutions affect the accuracy of GLAI esti- 
Table 1. Root mean square error (RMSE), coefficient of variation (CV = RMSE/mean GLAI), and determination coefficient $\left(R^{2}\right)$ of the relationships between vegetation indices, VIs (EVI, WDRVI ${ }_{\alpha=0.2}$ and $\mathrm{WDRVI}_{\alpha=0.1}$ ) and green leaf area index (GLAI). VIs were retrieved at the first day of the period of the 8- or 16-day composite (defined here as DOY) and at the day during the composite period when the best observation was recorded (defined here as day of pixel composite, DPC).

\begin{tabular}{|c|c|c|c|c|c|c|c|}
\hline \multicolumn{2}{|c|}{ Vegetation index and day of VIs retrieval } & \multicolumn{3}{|c|}{ MOD09A1, $500 \mathrm{~m}, 8 \mathrm{~d}$} & \multicolumn{3}{|c|}{ MOD13Q1, 250 m, 16 d; MOD09Q1, 250 m, 8 d } \\
\hline & & $\overline{\operatorname{RMSE}\left(\mathrm{m}^{2} \mathrm{~m}^{-2}\right)}$ & $\mathrm{CV}(\%)$ & $R^{2}$ & $\overline{\operatorname{RMSE}\left(\mathrm{m}^{2} \mathrm{~m}^{-2}\right)}$ & $\mathrm{CV}(\%)$ & $R^{2}$ \\
\hline EVI & DOY & 1.04 & 29.02 & 0.72 & 1.01 & 29.54 & 0.75 \\
\hline $\mathrm{WDRVI}_{\alpha=0.2}$ & DPC & 0.84 & 22.94 & 0.80 & 0.50 & 13.95 & 0.94 \\
\hline \multirow{2}{*}{ WDRVI $_{\alpha=0.1}$} & DOY & 1.07 & 29.91 & 0.70 & 0.92 & 26.91 & 0.79 \\
\hline & $\mathrm{DPC}$ & 0.90 & 24.50 & 0.77 & 0.50 & 14.08 & 0.93 \\
\hline
\end{tabular}

Table 2. Established relationships between green leaf area index (GLAI) and vegetation indices retrieved from three MODIS products. Root mean square error (RMSE), coefficient of variation, CV (RMSE/mean GLAI), and determination coefficients $\left(R^{2}\right)$ are also presented.

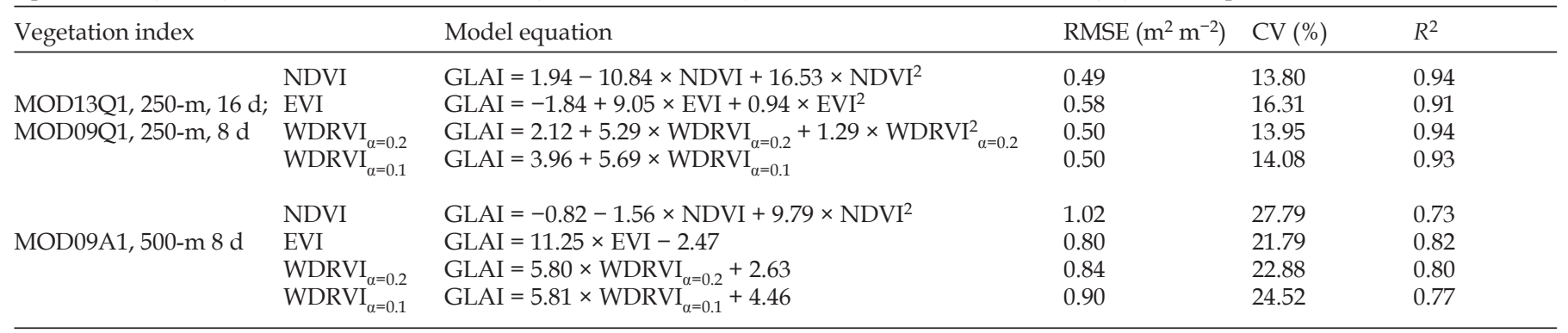

mation by different VIs. We compared relationships of VIs vs. GLAI, in which GLAI corresponded to (a) the first day of composite period (denoted as DOY), and (b) the day of pixel composite (denoted as DPC). The GLAI values were obtained by cubic spline interpolation of the relationship between destructively measured GLAI and DOY (Figure 3). In Table 1, determination coefficients $\left(R^{2}\right)$, root mean square errors of GLAI estimation, and coefficients of variation $(\mathrm{CV})$ are presented for relationships between GLAI and three vegetation indices, EVI and WDRVI $\alpha=0.2$ and WDRVI $\alpha=0.1$, retrieved from three MODIS products. Data taken in 2001 through 2004 under irrigated and rain-fed conditions were used in the analyses.

The main results of the analyses are as follows.

(i) When GLAI at day of pixel composite was used, RMSE of GLAI estimation decreased considerably compared with the use of GLAI taken at the first day of the composite. For 250-m 16-day composite data RMSE decreases two-fold.

(ii) An increase in spatial resolution (250-m vs. $500-\mathrm{m})$ led to increasing accuracy; RMSE decrease was $40 \%$ for EVI and $46 \%$ for WDRVI.

These findings help to explain results presented by Chen et al. (2006) who reported that data obtained from MODIS 250-m did not provide more accurate GLAI estimation over maize fields compared with MODIS 500-m resolution data. Our analysis showed similar RMSE of maize GLAI estimation using 250-m and 500-m resolution without the incorporation of DPC data. However, the results presented in Table 1 with the incorporation of DPC data clearly show that MODIS 250-m resolution did provide estimates that are more accurate over agricultural crops compared with MODIS 500-m resolution.

Relationships were established between vegetation indices and GLAI, taken at day of pixel composite, for all three MODIS products. Figure 6 presents the relationships between vegetation indices (NDVI, EVI, WDRVI ${ }_{\alpha=0.2}$ and WDRVI We. $_{\alpha}$ ) and GLAI under rain-fed and irrigated conditions in 2001-2004. The relationships between NDVI and GLAI were essentially nonlinear for all three MODIS products. While having high sensitivity to GLAI below $3 \mathrm{~m}^{2} \mathrm{~m}^{-2}$, NDVI tends to saturate as GLAI exceeds $3 \mathrm{~m}^{2} \mathrm{~m}^{-2}$. As GLAI varied from 4 to $6 \mathrm{~m}^{2} \mathrm{~m}^{-2}$, NDVI changed from 0.84 to 0.86 . This result is in accord with results of previous studies (Maas, 1993; Buschman and Nagel, 1993; Myneni et al., 1997; Gitelson et al., 2003). The relationships of EVI and WDRVI ${ }_{\alpha=0.2}$ with GLAI were also nonlinear; however, decreases in sensitivity of VIs to GLAI $>3 \mathrm{~m}^{2} \mathrm{~m}^{-2}$ were less pronounced than with NDVI. For all three MODIS products, WDRVI ${ }_{\alpha=0.1}$ had linear relationships with GLAI and determination coefficient above 0.93 for $250 \mathrm{~m}$ data and above 0.77 for $500 \mathrm{~m}$ data (Table 2).

An analysis of variance between the coefficients of the bestfit functions for three products (250-m 8- and 16-day composites and 500-m 8-day composite) combined vs. the coefficients obtained for each individual product showed that for 8- and 16-day 250-m products the relationships between all VIs used (NDVI, EVI and WDRVIs) and GLAI are statistically similar (NDVI: $p>0.58$; EVI: $p>0.5$, WDRVI $_{\alpha=0.2}: p>0.63$; WDRVI $_{\alpha=0.1}: p>0.80$ ). Thus, established equations (Table 2) can be applied to MODIS 250-m products with no re-parameterization. However, relationships between GLAI and VIs for $250-\mathrm{m}$ and $500-\mathrm{m}$ resolution products are statistically different with $\rho<0.01$ (Table 2). Important to note, for the same GLAI, all VIs are consistently higher for $250-\mathrm{m}$ products than for $500-\mathrm{m}$ products (Figure 6e-h). This is understandable taking into account that $500-\mathrm{m}$ data is contaminated by surrounding areas with no vegetation (roads) or less vegetation than in the fields as is seen in Figure 2.

The determination coefficient, $R^{2}$, and RMSE of GLAI estimation represent the dispersion of the points from the bestfit regression lines. They constitute measures of how good the regression model (best-fit function) is in capturing the relationship between GLAI and VIs. However, when the best-fit function is nonlinear, as in case of NDVI, EVI and WDRVI ${ }_{\alpha=0.2}$ (Figure 6), both $R^{2}$ and RMSE values may be misleading. For example, although the relationship of NDVI vs. GLAI showed values of $R^{2}$ above 0.90 (Table 2 and Figure 6a), the slope of the relationship decreased drastically as GLAI exceeded $3 \mathrm{~m}^{2} \mathrm{~m}^{-2}$. The relationships of GLAI vs. VIs had similar $R^{2}$ and RMSE (Table 2) but very different shapes (e.g., asymptotic behavior in NDVI vs. linear in WDRVI ${ }_{\alpha=0.1}$ ). Therefore, a different accuracy metric was needed to compare the performance of VIs in estimating GLAI over the whole range of its variation. We ap- 

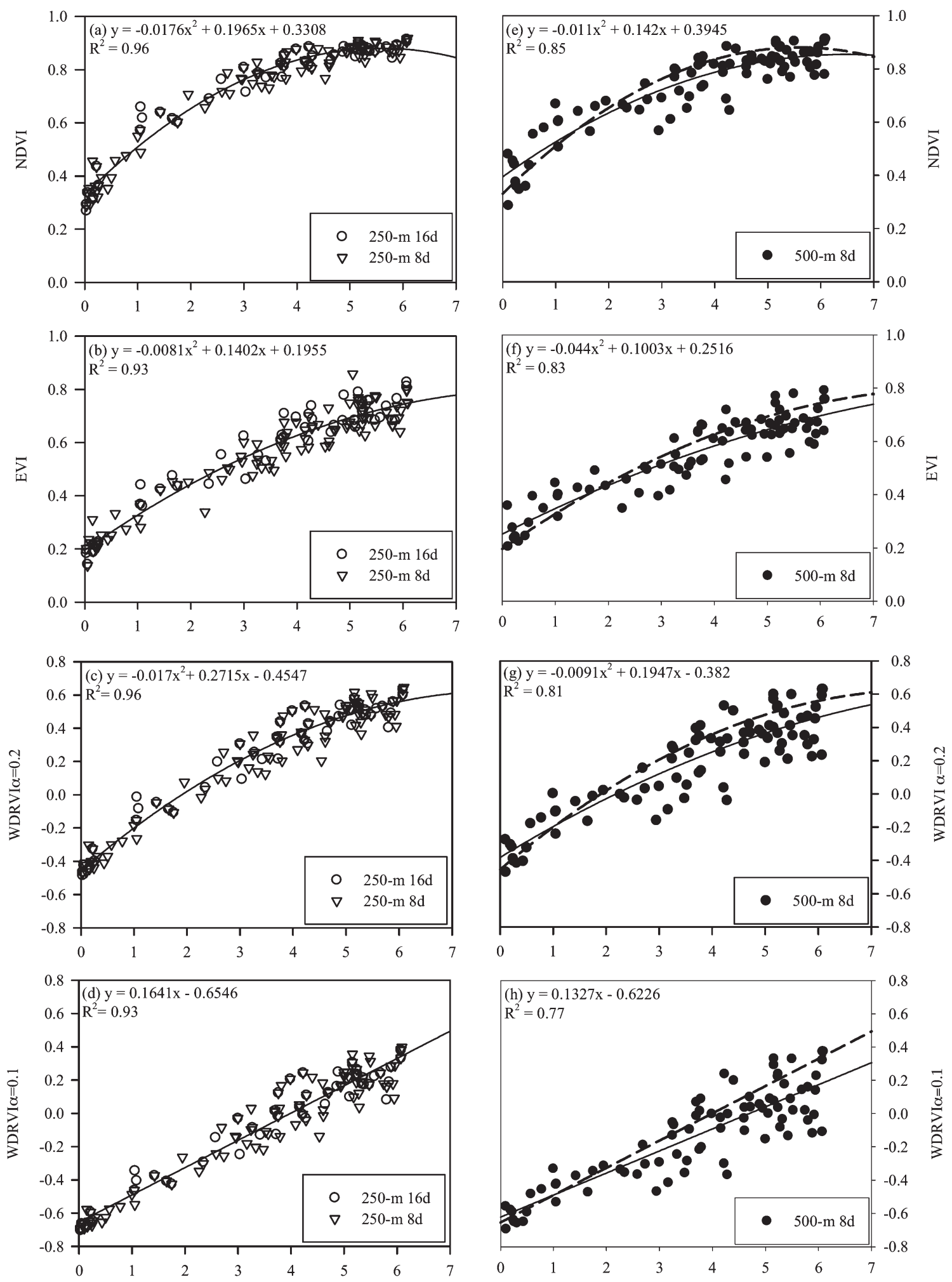

$\operatorname{GLAI}\left(\mathrm{m}^{2} \mathrm{~m}^{-2}\right)$

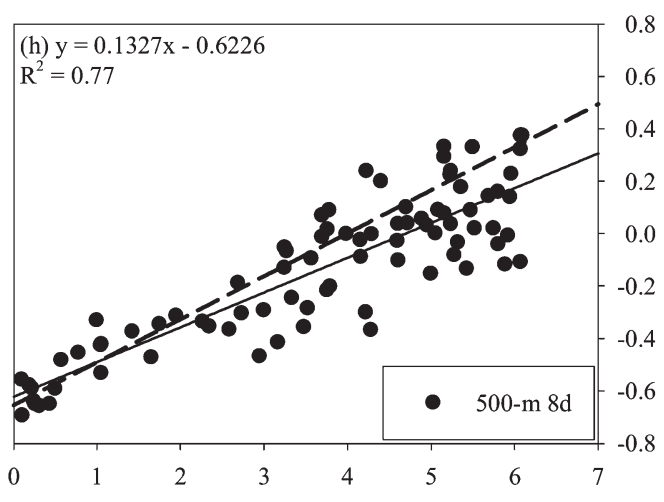

GLAI $\left(\mathrm{m}^{2} \mathrm{~m}^{-2}\right)$

Figure 6. Vegetation indices plotted vs. green leaf area index (GLAI) for 250-m resolution data (left column) and 500-m resolution (right column); solid lines are best-fit functions. Dashed lines are best-fit functions for 8- and 16-day 250-m resolution data plotted for comparison with 500-m data. (a) and (e) normalized difference vegetation index (NDVI), (b) and (f) enhanced vegetation index (EVI), (c) and (g) wide dynamic range vegetation index (WDRVI) with $\alpha=0.2,(\mathrm{~d})$ and $(\mathrm{h})$ wide dynamic range vegetation index (WDRVI) with $\alpha=0.1$.

plied the noise equivalent as an indicator of the accuracy of GLAI estimation that provides a metric accounting for both scattering of the points from the best-fit function and the slope of the best-fit function.
Figure 7 shows noise equivalent of GLAI estimation by different indices retrieved from MODIS 250-m 8- and 16-day composites. NDVI had the lowest NE (highest accuracy) when GLAI $<2.5 \mathrm{~m}^{2} \mathrm{~m}^{-2}$, while NE increased drastically when GLAI 


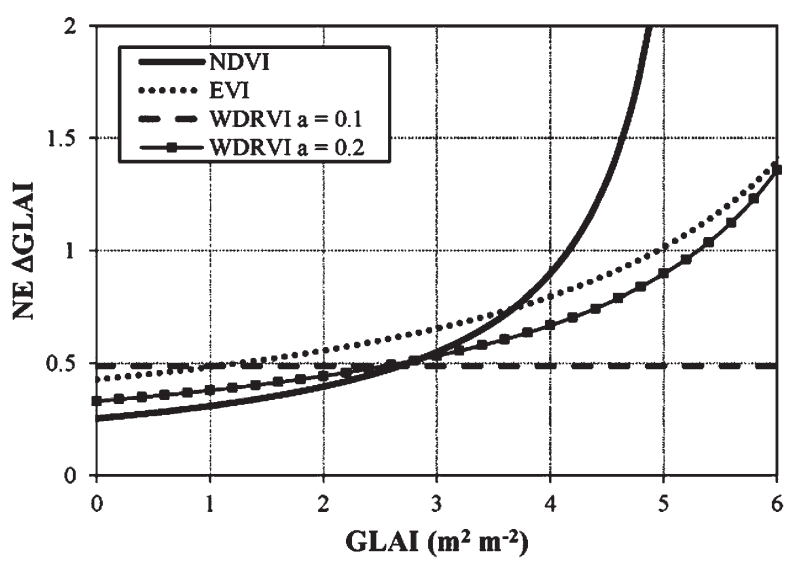

Figure 7. Noise equivalent of green LAI estimated by NDVI, EVI, WDRVI with $\alpha=0.1$ and $\alpha=0.2$, retrieved from MODIS surface reflectance 250-m 8-day composite (MOD09Q1) and MODIS vegetation index 250-m 16-day composite (MOD13Q1).

Table 3. Noise equivalent in $\mathrm{m}^{2} \mathrm{~m}^{-2}$ of green leaf area index (GLAI) estimation by vegetation indices calculated using 250-m 8- and 16-day composite MODIS products.

\begin{tabular}{lllll}
\hline GLAI $\left(\mathrm{m}^{2} \mathrm{~m}^{-2}\right)$ & NDVI & EVI & WDRVI $\alpha=0.2$ & WDRVI $\alpha=0.1$ \\
\hline 1 & 0.31 & 0.48 & 0.38 & 0.49 \\
2 & 0.4 & 0.56 & 0.44 & 0.49 \\
2.5 & 0.46 & 0.6 & 0.48 & 0.49 \\
3 & 0.55 & 0.66 & 0.53 & 0.49 \\
4 & 0.90 & 0.8 & 0.67 & 0.49 \\
5 & 2.43 & 1.01 & 0.89 & 0.49 \\
6 & & 1.39 & 1.36 & 0.49 \\
\hline
\end{tabular}

was above $3 \mathrm{~m}^{2} \mathrm{~m}^{-2}$. The behavior of the NE of WDRVI $\mathrm{I}_{\alpha=0.2}$ was almost the same as NDVI for GLAI $<2.5 \mathrm{~m}^{2} \mathrm{~m}^{-2}$, however, the rate of NE increase for GLAI $>3 \mathrm{~m}^{2} \mathrm{~m}^{-2}$ was much lower. The relationship WDRVI W $_{0.1}$ vs. GLAI was linear (Figure $6 \mathrm{~d}$ $\& \mathrm{~h}$, Table 2), thus, NE remained constant over the whole dynamic range of GLAI (Figure 7). It was the lowest among the VIs used for LAI $>3 \mathrm{~m}^{2} \mathrm{~m}^{-2}$. In Table 3 we presented NE values for different VIs corresponding to GLAI from 1 to $6 \mathrm{~m}^{2} \mathrm{~m}^{-2}$. It can be seen that NDVI was superior in estimating GLAI over the range from 0 to $2.5 \mathrm{~m}^{2} \mathrm{~m}^{-2}$ (NE was below $0.46 \mathrm{~m}^{2} \mathrm{~m}^{-2}$ ) and WDRVI ${ }_{\alpha=0.1}$ had the highest accuracy (NE below $0.49 \mathrm{~m}^{2} \mathrm{~m}^{-2}$ ) when GLAI $>3 \mathrm{~m}^{2} \mathrm{~m}^{-2}$. Thus, applying the NE metric allows direct quantitative comparison among different indices with different scales and dynamic ranges.

We validated the models for GLAI estimation using EVI and WDRVI ( $\alpha=0.1$ and $\alpha=0.2$ ) with independent data sets taken from 2005 through 2009. We did not validate the NDVI model due to its very low accuracy for estimating GLAI $>3 \mathrm{~m}^{2} \mathrm{~m}^{-2}$. VIs values from the validation data sets were used to calculate GLAI employing established calibrated equations (Table 2) and these predicted GLAI values were compared to GLAI measured destructively. Figures 8, 9, \& 10 show the results of the validations. The GLAI vs. EVI model was able to estimate GLAI with RMSE below $0.9 \mathrm{~m}^{2} \mathrm{~m}^{-2}$ for all MODIS products. The linear models of GLAI vs. WDRVI ${ }_{\alpha=0.1}$ and polynomial models of GLAI vs. WDRVI $\alpha=0.2$ brought RMSE below 0.87 for the $500-\mathrm{m}$ resolution product and were much more accurate in GLAI estimation using the $250-\mathrm{m}$ resolution products: RMSE was below $0.60 \mathrm{~m}^{2} \mathrm{~m}^{-2}$ (Figure 11). Validation results confirmed that more accurate estimates of maize GLAI can be obtained using data taken with higher spatial resolution: the 250-m (MOD13Q1 and MOD09Q1), compared to the MODIS product 500-m resolution (MOD09A1). The reason for higher uncertainties of GLAI estimation using
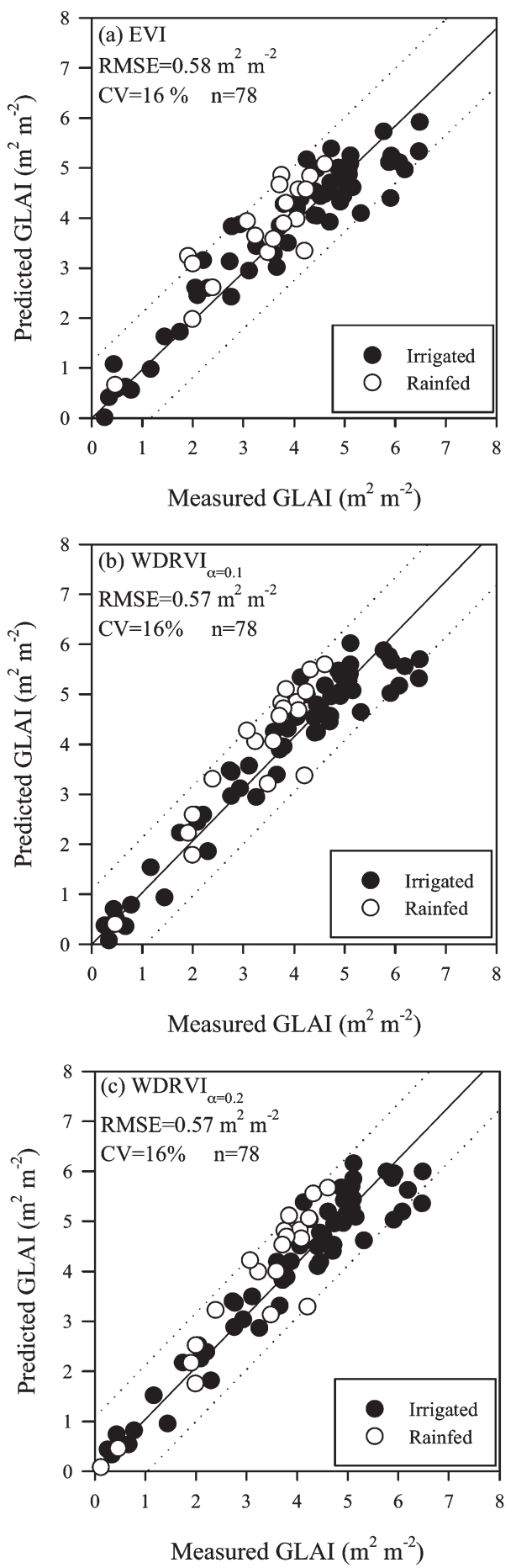

Figure 8. Green leaf area index (GLAI) predicted by established algorithms (Table 2) (a) enhanced vegetation index (EVI), and wide dynamic range vegetation index (WDRVI) with (b) $\alpha=0.1$ and (c) $\alpha=0.2$ plotted vs. measured GLAI of maize grown under irrigated and rainfed conditions from 2005 to 2009. VIs were retrieved from MODIS vegetation index 250-m 16-day product (MOD13Q1).

500-m resolution data is most likely signal contamination by surrounding areas (Figure 2).

WDRVI $(\alpha=0.1$ and $\alpha=0.2)$ and EVI allowed more accurate estimation of GLAI taken at DPC than has been reported in previous studies using MODIS 250-m resolution products. Doraiswamy et al. (2004) estimated maize GLAI with a RMSE of 1.11 and $0.63 \mathrm{~m}^{2} \mathrm{~m}^{-2}$ using MODIS 250-m and field canopy reflectance, respectively. They attributed the difference 

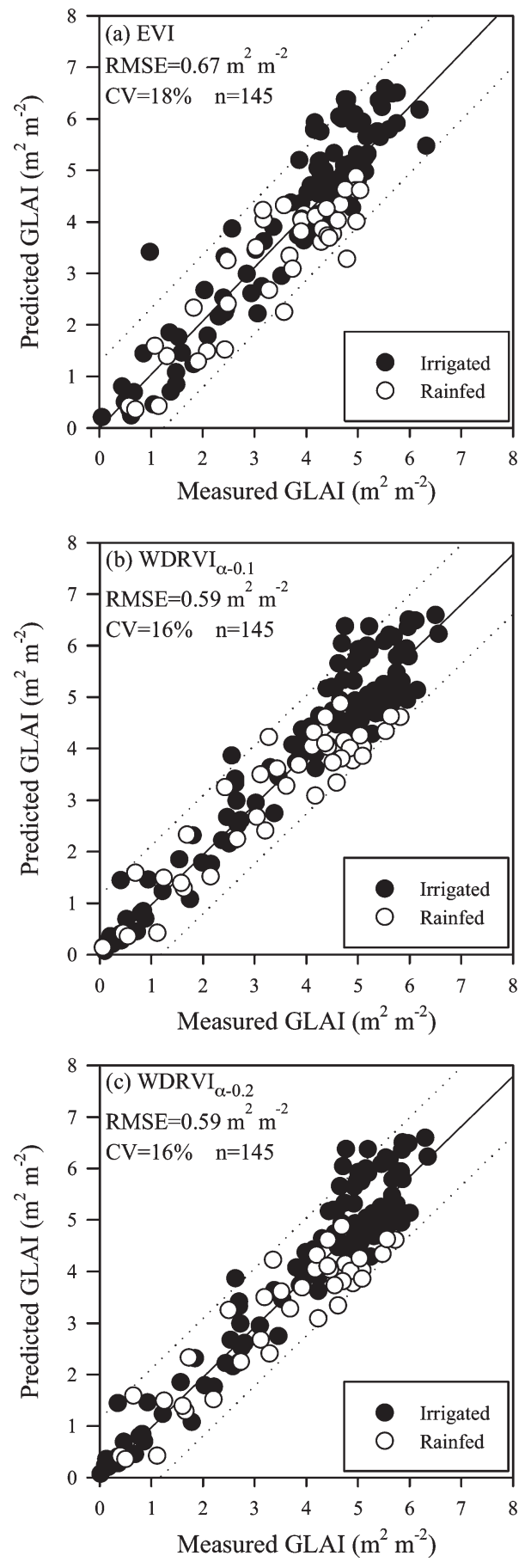

Figure 9. Green leaf area index (GLAI) predicted by established algorithms (Table 2) (a) enhanced vegetation index (EVI), and wide dynamic range vegetation index (WDRVI) with (b) $\alpha=0.1$ and (c) $\alpha=0.2$ plotted vs. measured GLAI of maize grown under irrigated and rainfed conditions from 2005 to 2009. VIs were retrieved from MODIS surface reflectance 250-m 8-day product (MOD09Q1).

in RMSE between field and satellite estimation to potential errors associated with MODIS atmospheric correction. On the other hand, Zhu et al. (2005) reported a linear relationship in grass between GLAI and 250-m resolution MODIS-retrieved EVI and NDVI with $R^{2}=0.82$ and 0.78 , respectively. Neither of these studies mentioned whether information on DPC was included in their analyses.

The results presented in this study clearly show that MODIS 250-m spatial resolution products (MOD13Q1 and
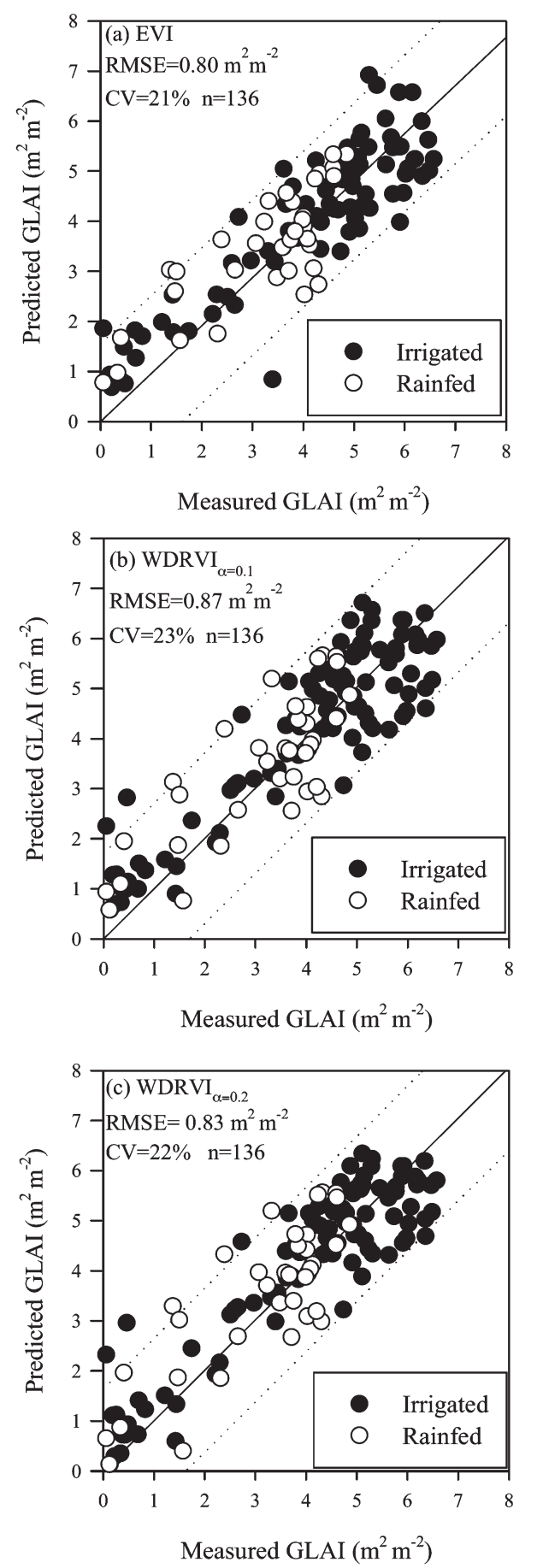

Figure 10. Green leaf area index (GLAI) predicted by established algorithms (Table 2) (a) enhanced vegetation index (EVI), and wide dynamic range vegetation index (WDRVI) with (b) $\alpha=0.1$ and (c) $\alpha=0.2$ plotted vs. measured GLAI of maize grown under irrigated and rainfed conditions from 2005 to 2009. VIs were retrieved from MODIS surface reflectance 500-m 8-day product (MOD009A1).

MOD09Q1) can provide more accurate estimates of critical growth stages and GLAI for crop modeling applications than the MODIS 500-m spatial resolution product (MOD09A1). Results obtained during nine years of observation showed that maize GLAI can be monitored during the entire growing season using the EVI and the $\mathrm{WDRVI}_{\alpha=0.2}$ quadratic models and $W_{D R V I}{ }_{\alpha=0.1}$ linear models using data retrieved from the MODIS VIs 16-day composite product (MOD13Q1). The MODIS surface reflectance 8 -day composite $250-\mathrm{m}$ product 
(MOD09Q1) brings more frequent observations that should provide an opportunity for better estimation of crop critical stages; however, knowledge of the DPC would dramatically enhance its utility in many agricultural applications.

The relationships of GLAI vs. VIs (Table 2) were developed on the basis of results obtained in three Nebraska sites during four years of observation in 2001-2004. The algorithms were validated using data obtained in 2005-2009. We cannot answer the question whether these equations can be applied with no re-parameterization to estimate GLAI in maize grown in different climatic conditions. However, the algorithms were developed and validated for maize grown under both irrigation management and rain-fed conditions. The nine-year study period represents wet years as well as normal and dry years, in which the maize in the rain-fed site might suffer from water stress to different degrees, while the maize in irrigated sites was relatively stress-free. In addition, the density of planting in the rain-fed site was much lower than in the irrigated sites in order to account for differences in water-limited attainable yield. Thus, during the nine years of observations the physiological conditions of crops varied drastically. Despite all these differences, as well as wide changes in weather conditions, in composition of incident irradiation, and in viewing zenith angle among others, the models presented in the paper were able to accurately estimate GLAI with RMSE below $0.60 \mathrm{~m}^{2} \mathrm{~m}^{-2}$. Thus, the models as presented may likely be applied for maize grown in different climatic conditions. However, further studies should address questions about whether the algorithms require re-parameterization or not.

\section{Conclusions}

This study evaluated performance of three MODIS products (MOD13Q1, MOD09A1, and MOD09Q1) to quantify green leaf area index in maize. The temporal resolution of MODIS data (period between two consecutive observations) for this study varied widely and reached 15 days for 8-day composites and 30 days for 16-day composites. Due to maize leaf area index dynamics and unpredictable changes in MODIS real temporal resolution, the inclusion of day of pixel composite is necessary to increase the accuracy of green leaf area index estimates in agricultural crops. Analysis of noise equivalent of established relationships between VIs and green leaf area index showed that accuracy of green leaf area index estimation by NDVI, EVI and $\mathrm{WDRVI}_{\alpha=0.2}$ varied significantly for different canopy densities. Among the vegetation indices studied, only $\mathrm{WDRVI}_{\alpha=0.1}$ had a linear relationship with green leaf area index and, thus, a constant noise equivalent value below $0.5 \mathrm{~m}^{2} \mathrm{~m}^{-2}$ over the whole range of green leaf area index from 0 to more than $6 \mathrm{~m}^{2} \mathrm{~m}^{-2}$. The established relationships using day of pixel composite data were validated by independent data sets taken in 20052009. Using MODIS 250-m resolution data, maize green LAI was predicted by EVI with RMSE below $0.7 \mathrm{~m}^{2} \mathrm{~m}^{-2}$ and by both WDRVIs with RMSE below $0.6 \mathrm{~m}^{2} \mathrm{~m}^{-2}$. Results also showed that MODIS 250-m resolution provides more accurate estimates of maize green leaf area index compared to MODIS 500-m resolution. Using MODIS 500-m resolution data allows estimates of green leaf area index with RMSE around $0.80 \mathrm{~m}^{2} \mathrm{~m}^{-2}$ by both EVI and WDRVI. Results from this study also suggested that the MOD09Q1 product could be the better product to monitor agricultural crops due to higher spatial and temporal resolutions; however, this product does not include information on day of pixel composite (collection 5).

Acknowledgments - We would like to thank Dave Scoby who led the field LAI measurements and two anonymous reviewers for excellent and very helpful comments and suggestions.

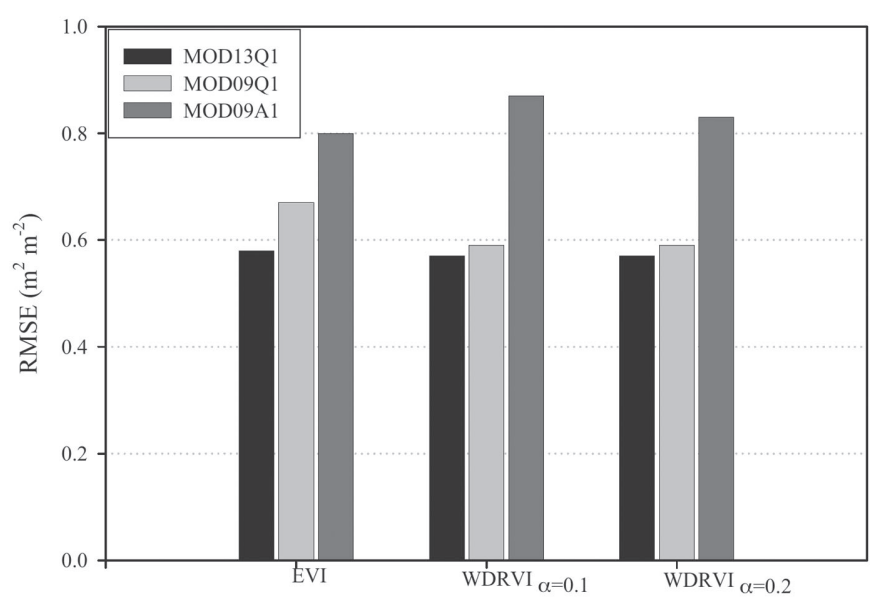

Figure 11. Root mean square error (RMSE) of green leaf area index prediction by established algorithms (Table 2) using MODIS 250-m 16-day (MOD13Q1), 250-m 8-day (MOD09Q1), and 500-m 8-day (MOD09A1) products.

\section{References}

Buschman, C., Nagel, E., 1993. In vivo spectroscopy and internal optics of leaves as basis for remote sensing of vegetation. Int. J. Remote Sens. 14, 711-722.

Chen, P.Y., Fedosejevs, G., Tiscareño-López, M., Arnold, J.G., 2006. Assessment of MODIS-EVI, MODIS NDVI and vegetation-NDVI composite data using agricultural measurements: an example at corn fields in Western Mexico. Environ. Monit. Assess. 119, 69-82.

Chen, P.Y., Srinivasan, R., Fedosejevs, G., Kiniry, J.R., 2003. Evaluating different NDVI composite techniques using NOAA-14 AVHRR data. Int. J. Remote Sens. 24 (17), 3403-3412.

Chen, P.Y., Srinivasan, R., Fedosejevs, G., Narasimhan, B., 2002. An automated cloud detection method for daily NOAA-14 AVRR data for Texas, USA. Int. J. Remote Sens. 23 (15), 2939-2950.

Dash, J., Curran, P.J., 2004. The MERIS terrestrial chlorophyll index. Int. J. Remote Sens. 25, 5003-5013.

Didan, K., Huete, A., 2006. MODIS Vegetation Index Product Series Collection 5 Change Summary; http://landweb.nascom. nasa.gov/QA_WWW/forPage/MOD13_VI_C5_Changes_Document_06_28_06.pdf

Doraiswamy, P.C., Hatfield, J.L., Jackson, T.J., Akhmedov, B., Prueger, J., Stern, A., 2004. Crop condition and yield simulations using Landsat and MODIS. Remote Sens. Environ. 92, 548-559.

Duchemin, B., Maisongrande, P., 2002. Normalisation of directional effects in 10-day global syntheses derived from VEGETATION/ SPOT: I. Investigation of concepts based on simulation. Remote Sens. Environ. 81, 90-100.

Fang, H., Liang, S., Hoogenboom, G., Teasdale, J., Cavigelli, M., 2008. Corn-yield estimation through assimilation of remotely sensed data into the CSM-CERES-Maize model. Int. J. Remote Sens. 29 (10), 3011-3032.

Funk, C., Budde, M., 2009. Phenologically-tuned MODIS NDVI-based production anomaly estimates for Zimbabwe. Remote Sens. Environ. 113 (1), 115-125.

Gitelson, A.A., 2011. Remote sensing estimation of crop biophysical characteristics at various scales. In: Thenkabail, P.S., Lyon, J.G., Huete, A. (Eds.), Hyperspectral Remote Sensing of Vegetation. Taylor and Francis, pp. 329-358 (chapter 15).

Gitelson, A.A., 2004. Wide dynamic range vegetation index for remote quantification of biophysical characteristics of vegetation. J. Plant Physiol. 161, 165-173.

Gitelson, A.A., Wardlow, B.D., Keydan, G.P., Leavitt, B., 2007. Evaluation of MODIS 250-m data for green LAI estimation in crops. Geophys. Res. Lett. 34, L20403, doi:10.1029/2007GL031620. 
Gitelson, A.A., Kaufman, Y., Merzlyak, M.N., 1996. Use of green channel in remote sensing of global vegetation from EOS-MODIS. Remote Sens. Environ. 58, 289-298.

Gitelson, A.A., Vĩna, A., Arkebauer, T.J., Rundquist, D.C., Keydan, G., Leavitt, B., 2003. Remote estimation of leaf area index and green leaf biomass in maize canopies. Geophys. Res. Lett. 30 (5), 1248.

Govaerts, Y.M., Verstraete, M.M., Pinty, B., Gobron, N., 1999. Designing optimal spec-tral indices: a feasibility and proof of concept study. Int. J. Remote Sens. 20, 1853-1873.

Hatfield, J.L., Gitelson, A.A., Schepers, J.S., Walthall, C.L., 2008. Application of spectral remote sensing for agronomic decisions. Agron. J. 100, 117-131.

Huete, A.R., Liu, H.Q., Batchily, K., van Leeuwen, W.J.D., 1997. A comparison of veg-etation indices over a global set of TM images for EOS-MODIS. Remote Sens. Environ. 59, 440-451.

Huete, A., Didan, K., Miura, T., Rodriguez, E.P., Gao, X., Ferreira, L.G., 2002. Overview of the radiometric and biophysical performance of the MODIS vegetation indices. Remote Sens. Environ. 83, 195-213.

Huete, A., Justice, C.O., van Leeuwen, W.J., 1999. MODIS Vegetation Index (MOD13), retrieved from http://modis.gsfc.nasa.gov/data/ atbd/atbd mod13.pdf

Kastens, J.H., Kastens, T.L., Kastens, D.L., Price, K.P., Martinko, E.A., Lee, R.Y., 2005. Image masking for crop yield forecasting using AVHRR NDVI time series imagery. Remote Sens. Environ. 99, 341356.

Jiang, Z., Huete, A.R., Didan, K.A., Miura, T., 2008. Development of a two-band enhanced vegetation index without a blue band. Remote Sens. Environ. 112, 3833-3845.

Li, A., Liang, S., Wang, A., Qin, J., 2007. Estimating crop yield from multi-temporal satellite data using multivariate regression and neural network techniques. Photogramm. Eng. Remote Sens. 73 (10), 1149-1157.

Lobell, D.B., Asner, G.P., 2004. Cropland distributions from temporal unmixing of MODIS data. Remote Sens. Environ. 93, 412-422.

Lunetta, R.L., Knight, F.K., Ediriwickrema, J., Lyon, J.G., Worthly, L.D., 2006. Landcover change detection using multi-temporal MODIS NDVI data. Remote Sens. Environ. 105, 142-154.

Maas, S.J., 1993. Within-season calibration of modeled wheat growth using remote sensing and field sampling. Agron. J. 85, 669-672.

Myneni, R.B., Nemani, R.R., Running, S.W., 1997. Estimation of global leaf area index and absorbed PAR using radiative transfer models. IEEE Trans. Geosci. Remote Sens. 35, 1380-1393.

Ritz, C., Streibig, J.C., 2008. Grouped data. In: Ritz, C., Streibig, J.C. (Eds.), Nonlinear Regression with R. Springer Science+Business Media, LLC, New York, NY, pp. 109-131.
Rochdi, N., Fernandes, R., 2010. Systematic mapping of leaf area index across Canada using 250-meter MODIS data. Remote Sens. Environ. 114, 1130-1135.

Rouse, J.W., Haas, R.H., Schell, J.A., Deering, D.W., 1974. Monitoring vegetation systems in the Great Plains with ERTS. In: Proc. Third Earth Resources Technology Satellite-1 Symposium, SP-351, Greenbelt, MD, pp. 309-317.

Sakamoto, T., Yokozawa, M., Toritani, H., Shibayama, M., Ishitsuka, N., Ohno, H., 2005. A crop phenology detection method using time-series MODIS data. Remote Sens. Environ. 95, 366-374.

Sedano, F., Gong, P., Ferrao, M., 2005. Land cover assessment with MODIS imagery in southern African Miombo ecosystems. Remote Sens. Environ. 98, pp. 429-441.

Shapiro, C.A., Ferguson, R.B., Hergert, G.W., Dobermann, A., Wortmann, C.S., 2001. Fertilizer suggestions for corn. Neb-Guide G74174-A. Cooperative Extension, Institute of Agriculture and Natural Resources. University of Nebraska-Lincoln, Lincoln, NE.

Swets, D.L., Reed, B.C., Rowland, J.R., Marko, S.E., 1999. A weighted least-squares approach to temporal smoothing of NDVI. In: ASPRS Annual Conference, Portand, Oregon, pp. 17-21.

Verma, S.B., Dobermann, A., Cassman, K.G., Walters, D.T., Knops, J.M., Arkebauer, T.J., Suyker, A.E., Burba, G.G., Amos, B., Yang, H., Ginting, D., Hubbard, K.G., Gitelson, A.A., Walter-Shea, E.A., 2005. Annual carbon dioxide exchange in irrigated and rain-fed maize-based agroecosystems. Agric. For. Meteorol. 131, 77-96.

Vermote, E.F., Kotchennova, S.Y., 2008. MOD09 (Surface Reflectance) User's Guide, retrieved from http://modis-sr.ltdri.org

Viña, A., Gitelson, A.A., 2005. New developments in the remote estimation of the fraction of absorbed photosynthetically active radiation in crops. Geophys. Res. Lett. 32, L17403, doi:10.1029/2005GL023647.

Wardlow, B.D., Kastens, J.H., Egbert, S.L., 2006. Using USDA crop progress data for the evaluation of greenup onset date calculated from MODIS 250-meter data. Photogramm. Eng. Remote Sens. 72 (11), 1225-1234.

Zhang, X., Friedl, M.A., Schaaf, C.B., Strahler, A.H., Hodges, J.C., Gao, F., Reed, B.C., Huete, A., 2003. Monitoring vegetation phenology using MODIS. Remote Sens. Environ. 84, 471-475.

Zhu, H., Luo, T., Yang, Y., 2005. MODIS-based seasonality and distribution of leaf area index of grassland of Gonghe Basin in QinghaiTibet plateau. Proc. SPIE 5976, 324-331. 